\title{
3 Research Square

\section{Interpretive Qualitative Evaluation Informs Research Participation and Advocacy Training Program for Seniors}

\author{
Allison A Bay ( $\sim$ allison.bay@emory.edu ) \\ Emory University School of Medicine https://orcid.org/0000-0002-7950-8506 \\ Madeleine E Hackney \\ Emory University School of Medicine https://orcid.org/0000-0003-1833-0051 \\ Hayley Silverstein \\ Emory University School of Medicine
}

Ariel R Hart

Emory University School of Medicine

David Lazris

Emory University School of Medicine

Tina Tian

Emory University School of Medicine

\section{Molly M. Perkins}

Emory University School of Medicine

\section{Research Article}

Keywords: Barriers, Facilitators, Educational Programs, Clinical Research, Participation

Posted Date: February 24th, 2022

DOI: https://doi.org/10.21203/rs.3.rs-1390988/v1

License: (c) (1) This work is licensed under a Creative Commons Attribution 4.0 International License. Read Full License 


\section{Abstract}

Background and Objectives: This paper reports on an interpretive evaluation conducted to identify successes and weaknesses of an 8-week educational intervention co-taught by medical students and faculty that was designed to foster communication between clinicians and researchers and ultimately increase participation in clinical research by older adults, including underrepresented groups. Weekly topics focused on age-related changes and health conditions, socio-contextual factors impacting aging populations, and wellness strategies.

Research Design and Methods: A post-intervention focus group was conducted with a representative group of eight older adults (mean age $=76 \pm 11$ years) from 51 total participants who completed the educational intervention. Participants were diverse in race, socio-economic status, education level, sex, and marital status.

Results: Thematic analyses show several participants were motivated by their personal experiences to join the study and continue coming to the seminars throughout the study. While participants viewed most aspects of the study as a success and stated that it was a productive learning experience, most participants had suggestions for improvements in the program content and implementation. Specifically, the composition of and direction to small breakout groups should be carefully considered and planned in this population, and attention should be paid to delivery of sensitive topics, e.g., death, dementia. A clear main benefit of this programmatic approach is the development of rapport among participants and between participants and clinical researchers.

Discussion and Implications: Results provide useful insights regarding improving participation among hard-to-reach and historically under-represented groups of older adults in clinical research. Future iterations of the DREAMS program and similar educational interventions can use these findings to improve the program and better achieve the programmatic objectives.

\section{Background}

The DREAMS project, which stands for "Developing a Research Participation Enhancement and Advocacy Training Program for Diverse Seniors", is a two part educational intervention that aimed to improve health literacy, increase participation in future clinical trials among older adults from multiple racial, ethnic and socioeconomic backgrounds and encourage participants to be research advocates. ${ }^{1}$ The DREAMS project sought to expand research participation in historically hard to reach populations, especially older adults, because limited diversity hinders progress in reducing health disparities. ${ }^{2}$ Decreasing health disparities is a national priority. ${ }^{3}$

Older adults have increased deficits and risk compared to younger individuals in multiple domains including sensory function, cognition, falls, cardiovascular disease, difficulty with performing activities of daily living, mental and psycho-social status, social and environmental challenges, and immune 
function. ${ }^{4}$ However, investigators have not always sufficiently considered older adults as important to include in clinical trials. ${ }^{5}$ Reasons for exclusion from research participation include ageism, a perceived lack of competence to participate, complications related to obtaining informed consent, and the need to allow more time for appointments to accommodate older, frailer individuals. ${ }^{6,7}$ Barriers to older adults' participation in research include transportation factors, unwillingness to undergo uncomfortable or risky procedures, poor vision, home responsibilities, and low educational attainment. ${ }^{8,9}$ As the percentage of adults 65 and older in the United States grows, healthcare disparities among older adults will continue to widen as more people are confronted with disabilities related to age, obesity, and environmental factors. ${ }^{10}$

Similar to the barriers facing older adults, racial inequality in clinical trials is a well-documented phenomenon. The National Institutes of Health $(\mathrm{NIH})$ Revitalization Act of 1993 requires NIH-funded clinical trials to include women and minorities as participants and assess outcomes by sex and race or ethnicity, however, targets for improving minority participation in research have not been met. ${ }^{11-14}$ Approximately $40 \%$ of the population in the United States identifies as a racial or ethnic minority, ${ }^{15}$ but these racial and ethnic minorities are under-represented in numerous domains of research including cystic fibrosis, ${ }^{16}$ cancer, ${ }^{17,18}$ bipolar disorder, ${ }^{19}$, diabetes, ${ }^{20}$ cardiovascular, ${ }^{21}$ biobanking, ${ }^{22}$ and other research despite evidence that many illnesses and poor health outcomes disproportionately burden under-represented minority groups. ${ }^{23}$ Focus groups with Black adults have suggested that fear and mistrust of the research and medical communities, ${ }^{24}$ lack of information, and knowledge of historical research-related aggrievances are major barriers to getting members of this community to volunteer as participants in studies. ${ }^{25}$ Research participation facilitators among Blacks include a desire to help others facing similar challenges and familiarity with the researchers and recruiters. ${ }^{25}$ Given the intersection of age and race, older, low income adults of racial and ethnic minorities are particularly vulnerable to adverse health outcomes. ${ }^{2}$ Given the fraught history of mistreatment of minority and disadvantaged groups by researchers ${ }^{26}$, it is critical to have open dialogues with members of these groups to discuss the importance of research participation and build trust in researchers and the clinical research process. ${ }^{27,28}$

Focus groups conducted as part of a qualitative formative evaluation aimed at identifying potential barriers and facilitators before implementation of DREAMS found that mistrust of the medical community and the belief that research was primarily conducted for profit as opposed to being for the benefit of patients were major barriers. ${ }^{29}$ This information was used to inform the implementation of the DREAMS program, which took place over one year in several cohorts of older adults, whose sociodemographic makeup matched the locale. The current paper reports findings from a retrospective interpretive qualitative evaluation conducted post-DREAMS with 8 DREAMS participants. This evaluation was designed to identify potentially needed modifications for future implementation of DREAMS and provide suggestions for improving the experience of diverse older adults throughout the clinical research process. 


\section{Methods}

This study was approved by the Emory University Institutional Review Board. All participants provided written informed consent before participation.

\section{Overview of the DREAMS Program}

The DREAMS project is an educational intervention developed to increase participation opportunities in all phases of the research process for older adults, defined as 55 years or older in the DREAMS program. DREAMS inspired by previous work of the authors, who had coordinated interactive lectures from university faculty for older adults over a number of years. DREAMS consisted of weekly 90 -minute sessions over eight consecutive weeks and was delivered via interactive seminar focusing on health and wellness and co-taught by researchers, faculty and medical students to educate participants about current translational and clinical aging research (Table 2). The first hour of each class consisted of a lecture followed by a question/answer opportunity. During the lecture, the medical student presented general information about the topic (E.g., macular degeneration) for the first half hour. The expert/faculty member presented the second half hour on research information about the topic (E.g., research on therapies for macular degeneration). The last half hour consisted of moderated, small group discussion. ${ }^{30}$ Participants were broken up into 4 or 5 breakout groups to discuss the information presented in the lecture. The presenter and moderators would each choose a group to sit with for the discussion, with the presenter encouraged to move to different groups if they were able. The goal of the small group discussion was to encourage deeper processing of the learned information.

\section{Qualitative Evaluation Design}

Prior to the DREAMS intervention, a formative qualitative evaluation was conducted using focus groups to identify potential barriers and facilitators to implementing the program, and results from this evaluation are presented elsewhere. ${ }^{29}$

The current work presents findings from an interpretive evaluation post- DREAMS. ${ }^{31}$ Afocus group was conducted to qualitatively evaluate the program from the standpoint of participants after completion of the DREAMS courses.$^{29}$ The supplemental material shows the interview guide items.

Focus group participants were derived from all the DREAMS participants, 51 older adults from Metro Atlanta who completed at least six of the eight lessons. These "completers' were 73.0+/- 9.8 years and 
24 (47.1\%) were nonwhite. Overall DREAMS participant characteristics are further detailed in another publication. ${ }^{30}$

\section{Recruitment for the DREAMS Project}

Adults age 55 years and older from across metro-Atlanta were recruited via several methods, aided by partner organizations. Study team and partners posted fliers, delivered presentations to stakeholders, and met with housing administrative staff who shared information with residents. Strong efforts were made to mirror participant diversity with that of the surrounding community. Of the program participants, $41.3 \%$ were Black. Of note, the Black population of the city of Atlanta ( $51.3 \%$ Black) and the greater Atlanta metro area is $34.3 \%$ Black. ${ }^{32}$

\section{Focus Group Participants}

Out of 51 participants who completed DREAMS, eight agreed to participate in the post-DREAMS focus group. Socio-demographic information can be found in Table 1. DREAMS was offered in four cohorts of approximately 20 to 25 participants, who attended lectures together. The three men and five women who participated were an average of 75.8+/-11.4 years, had 3+/-1.9 comorbidities, took $6+/-5.3$ medications, and mostly drove their own vehicle (75\%). $25 \%$ did not provide their own transportation indicating some individuals were present who had diminished independence and/or disability. Six of the participants were White, one was Black, and one was multiracial. Six participants were retired. Participants were at moderate risk for loss of function in performing activities of daily living (ADL), indicated by composite physical function (CPF) scores at or below $18(/ 24)$. All participants had at least some college education and were generally highly educated with $17.5+/-2$ years of education.

\section{Focus Group Questions}

The semi-structured guide administered to participants began with questions assessing their expectations regarding their participation in DREAMS. They were asked about their expected or unexpected experiences and/or outcomes (Interview Guide: Supplemental Material). We probed their thoughts on the process and design of DREAMS, diversity of DREAMS and research in general, the presenters and medical students, and the employ of small group discussions (breakout groups) after lectures. We finished by asking participants for recommendations on future lecture topics, changes to discussion group format, and any unsolicited thoughts on the program. Questions about strengths, weaknesses, and recommendations for future iterations of DREAMS were asked to assess the potential for translation into a larger public health program and provide basis for a future formative evaluation of expanded versions of DREAMS ${ }^{33}$ 


\section{Data Analysis}

The focus group conversation was recorded and transcribed verbatim. NVIVO 11 software was used in data analysis. Employing a thematic deductive and inductive approach to analyze data, ${ }^{34}$ in the first stage of analysis, we created a codebook of a priori codes based on the aims of the evaluation (e.g., to determine whether the program met expectations and identify areas for improvement). As analysis progressed, emergent themes were added to the codebook. Two primary coders independently coded the transcript. A secondary coder reviewed the coding of the primary coders and helped reconcile coding differences. These initial codes provided the foundation for final themedevelopment. ${ }^{35} \mathrm{The}$ following themes emerged from the codes: diverse learning expectations, community building, teaching and topics, and the efficacy of the small group format (Table 3).

\section{Results}

We present the emergent themes that resulted.

\section{Learning Expectations:}

Participants agreed that the program met their expectations. When participants were asked to think back to their expectations of DREAMS before they began the course, participants remembered having expectations focused mainly on learning topics related to aging, with 4 of 8 participants stating that aging was central to what they had anticipated learning. Many responses focused on specific disease states, with the most common being dementia. several participants reported that they had initially been interested in topics that focused on how aging would affect themselves or their loved ones. A Black woman stated that she "wanted to learn more about the process of aging and what life was like for me physically or mentally because my husband['s] ...father [was] buried about a year earlier with dementia. And I wanted to know what to look for in myself or in my husband and different issues that may come about." Another White woman (E7) in the group said that she wanted to learn about dementia because she "lost a couple of friends lately. And both of them were a little bit younger than [her] that have come down with Alzheimer's."

The second most common response (3 of 8) was that participants had no expectation other than learning something new or interesting. When asked to think about his initial expectations, a White male (E6) explained he "didn't really have any preconceived ideas... [and] did not know what to expect." Another White woman answered that she "didn't exactly know what to expect, but...thought it would be interesting and it has been very interesting." 


\section{Teaching and Topics:}

The quality of instructors, both clinicians/clinical scientists and medical students appealed to many of the participants. Participants stated how much they appreciated both the expertise of the professionals and the candor and intelligence of the medical students. One White woman (E7) stated that "It was unexpected to have like experts in the field. I thought maybe just anyone might be givin' [sic] the talk". Another participant (E5) "thought it was great to be able to talk to the doctors directly along with the nurses and the researchers."

When speaking about themedical students, one participant (E2) reported, "I have been, the last few years, a little despondent about what the new generation of doctors going to look like...But seeing the students that came, they were so bright and, so cheerful... that gave me a lot of hope for the future." Other participants agreed that the medical students were a joyful and positive part of their experience, with one stating "I've absolutely adopted [a medical student]. I want to take him home with me."

While the instructors were a favorable part of their experience, the lessons themselves received mixed reactions from these participants. Many aspects of the presentations were seen as positives such as the variety of topics that were covered and the diversity of the participant groups which allowed for an engaging discussion on "age, culture, everything and... really added a lot, cause it's so different for everyone." (E5). However, the variability of topics (Table 2) was seen by some participants as negative because they felt that (E9) "some of [the sessions] were better and some of them are not so good." A few participants wanted longer classes, which was interesting considering the classes were 90 minutes long. Other topics that participants wanted included emotional aging, anxiety, memory, technology, dental, hearing, and vision. However, participants admitted that it would be hard to make a course selection perfect for every participant.

\section{Community-building:}

The participants often stated that the program gave them a sense of purpose. They felt that the environment in the group-learning sessions was welcoming, and the presenters validated all their questions and encouraged futureparticipation. A Hispanic/Latina and Native American woman (E2), described presenters as being very responsive and having "dignified our questions." Specifically, the participants reported enjoying their experiences with the program and "look[ed] forward to coming to sessions, because it was no stress involved" (E2). 
Additionally, participants felt they could gain new relationships through the program in addition to learning about relevant, relatable topics that pertain to their age-group. A White woman (E7) said that she "made some wonderful friends" throughout the program. While three participants (E2, E4 and E5) did not believe that they made friends in the program, they said they looked forward to the sessions every week and that there were "lots of different people to interact with" and "thought that was real interesting to see the different people who could converse about certain things that were happening to them then and now or had happened to them before, [which was] very profound, better than making a friend."

Most participants proclaimed that they were excited to come every time and felt that the staff was "super friendly." A White woman (E5) appreciated that they were able to talk directly to people in the health professions. The participants agreed that the diversity of knowledge within the group and what was presented made the experience interactive, educational, and interesting, making them more curious about other topics relevant to their age-group and research that deals with older adults. Most participants also enjoyed their interactions with the medical students. However, a White man, (E1) expressed that he would have preferred that experts were present in the entire session (i.e., during the small group discussions) instead of the student because sometimes, he said, students "couldn't answer questions... even though they tried."

Four of 8 participants stated that they would do the program again if they had the opportunity to do so and would recommend their friends and colleagues participate in something similar. This percentage contrasts with that the majority of participants from the larger sample that strongly agreed that they enjoyed the program or would like to continue participating. ${ }^{30} \mathrm{~A}$ White man (E8) proclaimed that he knew he learned a lot and enjoyed the experience and that he would "tell anyone who wanted to do it, 'come on."'

\section{The small group ("breakout") format does not work for everyone:}

Some participants felt that the small breakout groups held in the last half hour of the sessions was not very effective. Several focus group participants felt they were missing critical information if they were not placed in the small group with the expert presenter. A White man (E6) felt that the small groups may have limited discussion especially if some participants were shy and felt "pressured by them" to seem intelligent. One participant (E2) stated that in small groups, "some people talk a lot," which alsolimited the amount that all participants could contribute to the discussions. 
One participant, E8 reported having had a hard time hearing in some of the presentation sessions. The same participant also did not like the small groups and would have preferred to have had outlines or provided notes for the breakout groups because he felt that the different small groups were not discussing the same topics. Three participants, E2, E4, and E5 also agreed that they would have preferred a question guide for small groups to provide more structure to the discussion groups.

Perhaps unsurprisingly given that hearing impairment is common among older adults, ${ }^{36}$ difficulty hearing the presenters was mentioned as a barrier to enjoying the sessions, although the planners of the program had been aware of such age-related issues. One participant E8 said "Hearing is one of the things older people have problems with" in reference to the speakers. One participant E2 agreed and stated "I couldn't hear [the presenters].

\section{Unexpected Outcomes and Other Experiences}

Aging and Death.

Five participants reported that some topics, along with the discussion about aging in general, caused anxiety. For example, one participant E4 reported that a friend who had started the DREAMS program dropped out after the session on Alzheimer's Disease because her mother had passed away from Alzheimer's. She said, "I'm not ready for that, because either I'm going to take care of my husband or he's going to take care of me." Also related to the Alzheimer's lecture, one participant E7 stated "I learned a lot...enough to scare me." Another participant E5 said "one thing that comes to my mind is the emotional part of aging...realizing you're getting there. And you know your friends are dying and you may be the last one alive...it can be very melancholy."

Surprisingly, 5 participants mentioned feeling that the 1.5-hour sessions were insufficient in length of time. Specifically, in certain sessions the presenters did not have time to cover all the material they had prepared. A participant, E4 stated "Not getting to the end of the packet of each presenter was the only thing I could think of as a negative." Three of the participants suggested that the sessions would have been better if they had been a full two hours long.

\section{Recruitment}

Although not central to the content of DREAMS, knowing which recruitment strategies were most successful was of interest. When the facilitator asked, "how did you find out about this study," responses 
show that the most frequent way participants became involved in this DREAMS research study was through outreach conducted by research staff. Additionally, others saw a flyer promoting the study or were previously interested in the topic due to extraneous personal circumstances, e.g., being interested in dementia because a loved one has dementia.

\section{Discussion}

The growth of patient and public involvement in research has been substantiated by a holistic approach from service providers. Often recruitment fails to take into account what participants hope to gain when entering medical studies. ${ }^{37}$ This interpretive evaluation provides valuable insights into how to facilitate educational programs for older adults and meet expectations through facilitating their needs and desires during the experience. Our work agrees with other studies on the usefulness of examining program implementation processes from the perspective of different individuals. ${ }^{38}$

During this post-DREAMS focus group, several important barriers and facilitators for older adults for participation in research, expectations for the DREAMS program, and suggestions for future educational interventions designed for older adult audiences were elucidated.

\section{Implementation Expectations:}

Four of 8 focus group participants expected to learn more information about aging, particularly information related to dementia before beginning the DREAMS program. Others (3/8), although they did not have specific expectations, anticipated learning something new and interesting. The participants' responses underscore the importance of providing interesting and relevant information. Further, although participants knew and expected aging-related topics, some participants (both in the larger group and in the focus group) found the material emotionally difficult to contemplate and might have preferred not to think about it, given it brought up ideas of death and functional decline.

\section{Implementation Successes:}

Social factors, including engagement with presenters and other participants, enhanced participants' experience in DREAMS. Most participants found the clinical professionals and medical students who taught the lessons to be an engaging and a favorable part of their overall experience. Participants made connections with each other and with researchers. Seeing the other members of their course cohort was a pleasure for some and may have enhanced compliance and attendance at the program. 
Variability of lesson topics was perceived as both a positive and negative aspect of DREAMS. The diversity of topics contributed to a lively and intriguing discussion. However, variability among topics resulted in participants' lack of interest in some of the lessons, possibly due to lack of relevance for the individual. Unsurprisingly, in this audience with mixed interests and backgrounds, although the program had an overall theme of aging, developing topics that engaged all participants was a challenge and perhaps not easily addressed. To achieve the goals of DREAMS, DREAMS provided an opportunity for these older adults to cognitively engage deeply, which could have positive downstream effects. Importantly, it may be that the courses themselves and the information that got passed on was less important than the building of relationships, and emerging rapport between participants themselves as well as between participants and health professionals/researchers.

\section{Maintenance and Future Iterations of DREAMS.}

A definitive area for improving future educational programs for older adults is to be more sensitive to agerelated fears and stigma, e.g., impending death, cognitive declines and sensory dysfunction. Given that several participants found discussion of aging to be emotional and/or stressful, more emphasis could be given to the positive aspects of aging such as experience, knowledge, being a resource, etc. to offset discussions about age-related diseases, which was well covered by the medical research professionals. While it is typical for medical researchers to focus on pathology, and it is important to educate the patient groups about pathological processes, maintaining independence and quality of life initiatives are of vital importance for a growing and thriving older adult population Additionally, including information about ways to combat ageism and refute negative cultural views about older adults may have been helpful.

Another area for improvement is providing more guidelines for communication within the setting, particularly regarding the small group discussions, which were perceived to have been limited by who the leader/moderator of the small group was, in addition to the differing personality types present in each group. Specifically, those who were not loud or assertive were not able to contribute their ideas as much as they would have liked. A potential solution to this problem is to create a more structured and uniform discussion, including a question guide, a more active moderator and have the presenter rotate to each small group and spend equal time with the groups. Furthermore, time management on the part of the moderators and presenters may improve satisfaction with in-person educational programs.

\section{LIMITATIONS}


We acknowledge some important limitations. Including only $25 \%$ minority participants in the focus group, although there was nearly $50 \%$ representation in the larger group, limits the generalizability of the findings. Future studies should include more individuals from underrepresented groups, older adults with lower socioeconomic status, and individuals with less or low education. These groups are often difficult to reach and recruit into studies; yet would increase generalizability and the applicability of the findings to inclusion of disadvantaged groups in research. The study occurred in a large metropolitan area of Atlanta, which also limits generalizability of these results to this region. In this study, we observed few racial and ethnic differences in response patterns, shown in other work. ${ }^{39}$

\section{FUTURE DIRECTIONS}

This paper provides important knowledge for future implementation of DREAMS.. Future efforts to improve participation of older adults should cultivate an environment for community building and personal growth, through the positive and open attitude of leaders and researchers and medical professionals in training and providing meaningful opportunities for interaction between older individuals from diverse backgrounds.

\section{Declarations}

Ethics Approval and Consent to Participate: This study was approved by the Emory University Institutional Review Board. All participants provided written informed consent before participation.

Consent for Publication: Not applicable.

Availability of Data and Materials: The datasets used and analyzed during the current study are available from the corresponding author upon reasonable request.

Competing Interest: The authors declare no competing interests.

Funding: This work was supported by the Patient Centered Outcomes Research Institute (PCORI) [grant 1099-EU]; and the National Parkinson Foundation [grant A01]. The funding body played no role in the design of the study and collection, analysis, and interpretation of data and in writing the manuscript.

Author's Contributions: $\mathrm{MH}, \mathrm{AB}, \mathrm{DL}, \mathrm{HS}, \mathrm{TT}, \mathrm{MP}, \mathrm{AR}$

$\mathrm{MH}$ and MP conceived the study, $A B, D L, H S, T T$, and $A R$ implemented the study and performed data collection. DL and AB drafted the manuscript. MH and MP reviewed and edited final drafts. All authors have read and approved the manuscript in this form. 
Acknowledgements: We would like to thank the participants and staff for their participation in this work..

\section{References}

1. Hackney ME, Perkins MM, Dillard R, Hart A. DREAMS Toolkit. In:2016.

2. Kaiser BL, Thomas GR, Bowers BJ. A Case Study of Engaging Hard-to-Reach Participants in the Research Process: Community Advisors on Research Design and Strategies (CARDS)(R). Res Nurs Health. 2017;40(1):70-9.

3. Purnell TS, Calhoun EA, Golden SH, et al. Achieving Health Equity: Closing The Gaps In Health Care Disparities, Interventions, And Research. Health Affairs. 2016;35(8):1410-5.

4. Jaul E, Barron J. Age-Related Diseases and Clinical and Public Health Implications for the 85 Years Old and Over Population. Front Public Health. 2017;5:335-5.

5. Talarico L, Chen G, Pazdur R. Enrollment of elderly patients in clinical trials for cancer drug registration: a 7-year experience by the US Food and Drug Administration. J Clin Oncol. 2004;22(22):4626-31.

6. Jacelon C. Older adults' participation in research. Nurse researcher. 2007;14:64-73.

7. Barron JS, Duffey PL, Byrd LJ, Campbell R, Ferrucci L. Informed consent for research participation in frail older persons. Aging Clinical Experimental Research. 2004;16(1):79-85.

8. Marcantonio ER, Aneja J, Jones RN, et al. Maximizing Clinical Research Participation in Vulnerable Older Persons: Identification of Barriers and Motivators. Journal of the American Geriatrics Society. 2008;56(8):1522-7.

9. Goodrow BA. Limiting Factors in Reducing Participation in Older Adult Learning Opportunities. The Gerontologist. 1975;15(5_Part_1):418-22.

10. lezzoni LI. Eliminating health and health care disparities among the growing population of people with disabilities. Health Aff (Millwood). 2011;30(10):1947-54.

11. Burchard EG, Oh SS, Foreman MG, Celedón JC. Moving toward true inclusion of racial/ethnic minorities in federally funded studies. A key step for achieving respiratory health equality in the United States. American journal of respiratory critical care medicine. 2015;191(5):514-21.

12. Geller SE, Koch AR, Roesch P, Filut A, Hallgren E, Carnes M. The More Things Change, the More They Stay the Same: A Study to Evaluate Compliance With Inclusion and Assessment of Women and Minorities in Randomized Controlled Trials. Acad Med. 2018;93(4):630-5.

13. Monitoring Adherence To The NIH Policy On The Inclusion Of Women And Minorities As Subjects. In Clinical Research. In: Health DoHaHSNIo, ed2010.

14. Chen MS Jr, Lara PN, Dang JH, Paterniti DA, Kelly K. Twenty years post-NIH Revitalization Act: enhancing minority participation in clinical trials (EMPaCT): laying the groundwork for improving minority clinical trial accrual: renewing the case for enhancing minority participation in cancer clinical trials. Cancer. 2014;120(0 7):1091-6. Suppl 7(.

15. Population Estimates J 1, 2019. In: Bureau UC, ed2019. 
16. McGarry ME, McColley SA. Minorities Are Underrepresented in Clinical Trials of Pharmaceutical Agents for Cystic Fibrosis. Ann Am Thorac Soc. 2016;13(10):1721-5.

17. Murthy VH, Krumholz HM, Gross CP. Participation in cancer clinical trials: race-, sex-, and age-based disparities. JAMA. 2004;291(22):2720-6.

18. Wallington SF, Dash C, Sheppard VB, et al. Enrolling Minority and Underserved Populations in Cancer Clinical Research. American Journal of Preventive Medicine. 2016;50(1):111-7.

19. Akinhanmi MO, Biernacka JM, Strakowski SM, et al. Racial disparities in bipolar disorder treatment and research: a call to action. Bipolar Disorders. 2018;20(6):506-14.

20. Sherman LD, Hawkins JM, Bonner T. An Analysis of the Recruitment and Participation of African American Men in Type 2 Diabetes Self-Management Research: A Review of the Published Literature. Social Work in Public Health. 2017;32(1):38-48.

21. Nooruddin M, Scherr C, Friedman P, et al. Why African Americans say "No": A Study of Pharmacogenomic Research Participation. Ethn Dis. 2020;30(Suppl 1):159-66.

22. Kim P, Milliken EL. Minority Participation in Biobanks: An Essential Key to Progress. Vol 1987. New York, New York Humana Press; 2019.

23. Schmotzer GL. Barriers and facilitators to participation of minorities in clinical trials. Ethn Dis. 2012;22(2):226-30.

24. Smirnoff $M$, Wilets I, Ragin DF, et al. A paradigm for understanding trust and mistrust in medical research: The Community VOICES study. AJOB Empir Bioeth. 2018;9(1):39-47.

25. Hughes TB, Varma VR, Pettigrew C, Albert MS. African Americans and Clinical Research: Evidence Concerning Barriers and Facilitators to Participation and Recruitment Recommendations. Gerontologist. 2017;57(2):348-58.

26. Scharff DP, Mathews KJ, Jackson P, Hoffsuemmer J, Martin E, Edwards D. More than Tuskegee: understanding mistrust about research participation. Journal of health care for the poor underserved. 2010;21(3):879-97.

27. Saadi A, Kim AY, Menkin JA, Carrillo CA, Reyes CE, Sarkisian CA. Mistrust of Researchers Correlates with Stroke Knowledge among Minority Seniors in a Community Intervention Trial. Journal of Stroke Cerebrovascular Diseases. 2020;29(1):104466.

28. Yeager DS, Purdie-Vaughns V, Hooper SY, Cohen GL. Loss of Institutional Trust Among Racial and Ethnic Minority Adolescents: A Consequence of Procedural Injustice and a Cause of Life-Span Outcomes. Child Development. 2017;88(2):658-76.

29. Perkins MM, Hart A, Dillard RL, Wincek RC, Jones DE, Hackney ME. A Formative Qualitative Evaluation to Inform Implementation of a Research Participation Enhancement and Advocacy Training Program for Diverse Seniors: The DREAMS Program. Journal of Applied Gerontology. 2019;38(7):959-82.

30. Dillard RL, Perkins M, Hart A, et al. Research Advocacy Training Program Benefits Diverse Older Adults in Participation, Self-Efficacy and Attitudes toward Research. Prog Community Health Partnersh. 2018;12(4):367-80. 
31. Royse D, Thyer B, Padgett D. Program Evaluation: An Introduction. Belmont: Wadsworth; 2010.

32. 2019 Population Estimates. U.S. Census Bureau;2018.

33. Stetler $\mathrm{CB}$, Legro MW, Wallace $\mathrm{CM}$, et al. The role of formative evaluation in implementation research and the QUERI experience. J Gen Intern Med. 2006;21(Suppl 2(Suppl 2):1-8.

34. Fereday J, Muir-Cochrane E. Demonstrating Rigor Using Thematic Analysis: A Hybrid Approach of Inductive and Deductive Coding and Theme Development. International Journal of Qualitative Methods. 2006;5(1):80-92.

35. Guest G, MacQueen KM, Namey EE. Applied Thematic Analysis. In: Thousand Oaks, California2012: https://methods.sagepub.com/book/applied-thematic-analysis. Accessed 2020/02/26.

36. Ciorba A, Bianchini C, Pelucchi S, Pastore A. The impact of hearing loss on the quality of life of elderly adults. Clin Interv Aging. 2012;7:159-63.

37. Dawson S, Campbell SM, Giles SJ, Morris RL, Cheraghi-Sohi S. Black and minority ethnic group involvement in health and social care research: A systematic review. Health Expect. 2018;21(1):3-22.

38. da Costa Kerber NP, Kirchhof AL, Cezar-Vaz MR, da Silveira RS. Right of the citizen and evaluation of health services: theoretical-practical approaches. Rev Lat Am Enfermagem. 2010;18(5):1013-9.

39. Bay A, Prizer L, Orusa A, Hart A, Perkins M, Hackney M. Effects of a Health Education and Research Participation Enhancement Program on Participation and Autonomy in Diverse Older Adults. Gerontology and Geriatric Medicine. 2020.

\section{Tables}




\begin{tabular}{|c|c|}
\hline Variable & N (\%)/ Mean (SD) \\
\hline English First Language & 7 \\
\hline \multicolumn{2}{|l|}{ Race/Ethnicity } \\
\hline White & 6 \\
\hline Black & 1 \\
\hline Multiracial & 1 \\
\hline \multicolumn{2}{|l|}{ Occupation Status } \\
\hline Full Time & 1 \\
\hline Part Time & 1 \\
\hline Homemaker & 1 \\
\hline Retired & 5 \\
\hline Years Retired, $M(S D)^{1}$ & $22.2(21.9)$ \\
\hline Education & 17.3 \\
\hline \multicolumn{2}{|l|}{ Assistive Device (Walking) } \\
\hline Always & 1 \\
\hline Sometimes & 3 \\
\hline Age in Years & $75.8(11.4)$ \\
\hline Number of Comorbidities & $3(1.9)$ \\
\hline Sex, M/F & $3 \mathrm{M} / 5 \mathrm{~F}$ \\
\hline \multicolumn{2}{|l|}{ Marital Status } \\
\hline Single & 1 \\
\hline Married & 3 \\
\hline Separated/Divorced & 1 \\
\hline Widowed & 3 \\
\hline \multicolumn{2}{|l|}{ Housing } \\
\hline House/Apt/Condo & 3 \\
\hline Independent Senior Housing & 4 \\
\hline Assistant Living & 1 \\
\hline \multicolumn{2}{|l|}{ Transportation } \\
\hline Drive Own Vehicle & 6 \\
\hline Family/Friends Drive & 1 \\
\hline Transport Service & 1 \\
\hline Composite Physical Function/24 & $17.6(5.4)$ \\
\hline Number of Prescription Medications & $6(5.3)$ \\
\hline \multicolumn{2}{|c|}{$\begin{array}{l}\text { Table 1: This table shows a descriptive summary of the focus group participants }(\mathrm{n}=8) \text {. All } \\
\text { participants were healthy older adults (HOA). The average participant was } 56 \text { years } \\
\text { old, white, and female who has some college education or holds a master's degree. } 1) \\
\text { Average excludes those who are not yet retired. }\end{array}$} \\
\hline
\end{tabular}




\begin{tabular}{|c|c|c|c|c|}
\hline Session & Course A & Course B & Course C & Course D \\
\hline $\begin{array}{l}\text { Week } \\
1\end{array}$ & $\begin{array}{l}\text { Research and } \\
\text { Creativity in } \\
\text { Later Life }\end{array}$ & $\begin{array}{l}\text { Research and } \\
\text { Creativity in } \\
\text { Later Life }\end{array}$ & $\begin{array}{l}\text { Research and } \\
\text { Creativity in Later } \\
\text { Life }\end{array}$ & $\begin{array}{l}\text { Research and } \\
\text { Creativity in Later } \\
\text { Life }\end{array}$ \\
\hline Week 2 & $\begin{array}{l}\text { Eyelid Ptosis } \\
\text { and the } \\
\text { Impairment of } \\
\text { Vision }\end{array}$ & $\begin{array}{l}\text { Bladder Matters } \\
\text { in Aging } \\
\text { Research }\end{array}$ & $\begin{array}{l}\text { Role of Commensal } \\
\text { Microbiota in Health } \\
\text { Span }\end{array}$ & $\begin{array}{l}\text { Role of Commensal } \\
\text { Microbiota in Health } \\
\text { Span }\end{array}$ \\
\hline Week 3 & $\begin{array}{l}\text { End of Life, } \\
\text { Palliative Care, } \\
\text { Assisted Living }\end{array}$ & $\begin{array}{l}\text { Dementia Family } \\
\text { Caregiver } \\
\text { Research }\end{array}$ & $\begin{array}{l}\text { Thai Chi Studies: } \\
\text { What have we } \\
\text { Learned }\end{array}$ & $\begin{array}{l}\text { Macular } \\
\text { Degeneration- Fact or } \\
\text { Fiction }\end{array}$ \\
\hline Week 4 & $\begin{array}{l}\text { Hand Motor } \\
\text { Function }\end{array}$ & $\begin{array}{l}\text { Social } \\
\text { Determinants of } \\
\text { Health and } \\
\text { Disparities }\end{array}$ & $\begin{array}{l}\text { Neuromechanics } \\
\text { Principles in } \\
\text { Rehabilitation }\end{array}$ & $\begin{array}{l}\text { Patient Perception of } \\
\text { the Discharge } \\
\text { Process }\end{array}$ \\
\hline Week 5 & $\begin{array}{l}\text { Cardiovascular } \\
\text { Health }\end{array}$ & $\begin{array}{l}\text { Research in } \\
\text { Specialized } \\
\text { Nutrition } \\
\text { Support }\end{array}$ & Cognition in Aging & $\begin{array}{l}\text { Thai Chi Studies: } \\
\text { What have we } \\
\text { Learned }\end{array}$ \\
\hline Week 6 & $\begin{array}{l}\text { Dementia Family } \\
\text { Caregiver } \\
\text { Research }\end{array}$ & $\begin{array}{l}\text { Role of } \\
\text { Commensal } \\
\text { Microbiota in } \\
\text { Health Span }\end{array}$ & \begin{tabular}{|l|} 
Eye health \\
\end{tabular} & $\begin{array}{l}\text { Cognition, } \\
\text { Anesthesia and Older } \\
\text { Adults }\end{array}$ \\
\hline Week 7 & $\begin{array}{l}\text { Role of } \\
\text { Commensal } \\
\text { Microbiota in } \\
\text { Health Span }\end{array}$ & $\begin{array}{l}\text { Common Causes } \\
\text { of Vision Loss }\end{array}$ & $\begin{array}{l}\text { Cognition, } \\
\text { Anesthesia and Older } \\
\text { Adults }\end{array}$ & $\begin{array}{l}\text { Pneumococcal } \\
\text { Carriage Study in the } \\
\text { Elderly }\end{array}$ \\
\hline Week 8 & $\begin{array}{l}\text { Urinary } \\
\text { Incontinence }\end{array}$ & $\begin{array}{l}\text { End of Life, } \\
\text { Palliative Care, } \\
\text { Assisted Living }\end{array}$ & $\begin{array}{l}\text { Balance and Falls in } \\
\text { Individuals with } \\
\text { Parkinson's Disease }\end{array}$ & $\begin{array}{l}\text { Balance and Falls in } \\
\text { Individuals with } \\
\text { Parkinson's Disease }\end{array}$ \\
\hline
\end{tabular}




\begin{tabular}{|l|l|}
\hline Table 3: Recurrent Themes from Focus Group Answer \\
\hline Topic & Themes \\
\hline Community Building & $\begin{array}{l}\text { - Welcome environment } \\
\text { - Expectations met } \\
\text { - Questions were valid } \\
\text { - Gave a sense of purpose } \\
\text { - Enjoyed coming to presentations } \\
\text { - Diverse study population } \\
\text { - Relatable/ Friendly }\end{array}$ \\
\hline Small group format does not & $\begin{array}{l}\text { - Want more time with the presenter } \\
\text { - Small group may limit discussion, especially if shy } \\
\text { - Purpose of small group may not have been clear } \\
\text { - Possible added pressure on participants }\end{array}$ \\
\hline Enjoyed both student and & $\begin{array}{l}\text { - Students were friendly and caring, overall a positive } \\
\text { benefit }\end{array}$ \\
\hline Topics covered & $\begin{array}{l}\text { - Quality instructors } \\
\text { - Would prefer an expert to always be present even if a } \\
\text { student is teaching }\end{array}$ \\
\hline & $\begin{array}{l}\text { - Good variation of topics } \\
\text { - Learned a lot }\end{array}$ \\
\hline
\end{tabular}

\section{Supplementary Files}

This is a list of supplementary files associated with this preprint. Click to download.

- SupplementalMaterialDREAMSpostFGpaper.docx 